\title{
ON THE ZEROS OF A CLASS OF POLYNOMIALS
}

\author{
W. M. SHAH AND A. LIMAN
}

Abstract. In this paper we prove some results concerning the distribution of the zeros of a polynomial in the complex plane. Our results not only contain some known generalizations of Eneström-Kakeya theorem but also a variety of interesting results can be deduced from them by a fairly uniform procedure.

Mathematics subject classification (2000): 30C10, $30 \mathrm{C} 15$.

Key words and phrases: Polynomials, modulii of the zeros, Eneström-Kakeya theorem.

\section{REFERENCES}

[1] A. AzIZ, Q. G. MoHAMmAD, Zero-free regions for polynomials and some generalizations of EneströmKakeya theorem, Cand. Math. Bull., 27, (1984), 265-272.

[2] A. AzIZ, Q. G. MohammaD, On the zeros of a certain class of polynomials and related analytic functions, J. Math. Anal. Appl., 75, (1980), 495-502.

[3] A. AzIZ, W. M. SHAH, On the zeros of polynomials and related analytic functions, Glasnik Mate., 33, (1998), 173-184.

[4] G. T. CARGO, O. SHISHA, Zeros of polynomials and fractional order differences of their coefficients, J. Math. Anal. Appl., 7, (1963), 176-182.

[5] K. K. Dewan, M. BidKham, On the Eneström-Kakeya theorem, J. Math. Anal. Appl., 180, (1993), 29-36.

[6] R. B. GARDNER, N. K. GoviL, On the location of the zeros of a polynomial, J. Approx. Theory, 76, (1994), 286-292.

[7] N. K. GovIL, V. K. JaIN, On the Eneström-Kakeya theorem II, J. Approx Theory, 22, (1978), 1-10.

[8] N. K. GovIL, Q. I. RAHMAN, On the Eneström-Kakeya theorem II, Tohoku Math. J., 20, (1968), 126-136.

[9] N. K. GOVIL, Q. I. RAHMAN AND G. SCHMEISSER, On the derivative of a polynomial, Illinois, Math. Jour., 23, (1979), 319-329.

[10] A. Joyal, G. LABelle AND Q. I. Rahman, On the location of zeros of polynomials, Canad. Math. Bull., 10, (1967), 53-63.

[11] M. MARDEN, Geometry of Polynomials, IInd Ed. Math, Surveys 3, Amer. Math. Soc., Providence, RI, (1966).

[12] G. V. Milovanovic, D. S. Mitrinovic and Th. M. Rassias, Topics in Polynomials, Extremal Problems, Inequalities, Zeros, World Scientific, Singapore (1994). 